\title{
West Haven-Yale Multidimensional Pain Inventory
}

National Cancer Institute

\section{Source}

National Cancer Institute. West Haven-Yale Multidimensional Pain Inventory. NCI

Thesaurus. Code C21151.

A 52 item chronic pain inventory. (Kerns 1985) 